\title{
LA ENFERMEDAD
}

La esclerosis lateral amiotrófica (ELA) es una enfermedad del sistema nervioso central, caracterizada por una degeneración progresiva de las neuronas motoras en la corteza cerebral (neuronas motoras superiores), tronco del encéfalo y médula espinal (neuronas motoras inferiores). La consecuencia es una debilidad muscular que avanza hasta la parálisis, extendiéndose de unas regiones corporales a otras. Amenaza la autonomía motora, la comunicación oral, la deglución y la respiración, aunque se mantienen intactos los sentidos, el intelecto y los músculos de los ojos. El paciente necesita cada vez más ayuda para realizar las actividades de la vida diaria, volviéndose más dependiente. el término esclerosis lateral amiotrófica lo utiliza Charcot por primera vez en 1874 y desde esas fechas la ELA se conoce universalmente con el epónimo de enfermedad de Charcot.

Las investigaciones etiológicas sugieren claramente factores exógenos más que genéticos en el origen de la enfermedad, fracasando, sin embargo, en la identificación de factores ambientales o dietéticos que expliquen esta agrupación de casos.

Entre un 5 y un $10 \%$ de todos los casos de ELA son familiares. La mayoría se heredan de manera autosómica dominante, aunque también se puede heredar de forma recesiva.

En 1993 Rosen identifica mutaciones en el cromosoma 21, más concretamente en el gen que codifica el enzima superóxido-dismutasa tipo 1 (SOD-1). En la actualidad se conocen más de 100 mutaciones distintas en este gen, que son responsables del 15 al 20\% de las formas familiares y, por tanto, del 1 al $2 \%$ de todas las formas de ELA.

Las manifestaciones clínicas de las formas familiares y esporádicas de ELA son idénticas. Las diferencias descritas entre ambas hacen referencia a la edad de inicio (unos 10 años antes como media en los casos familiares), a la incidencia según el sexo (predominio de varones en las formas esporádicas e igualdad para ambos sexos en las familiares) y a la extensión de las lesiones microscópicas (anomalías en los cordones posteriores y en otros núcleos medulares) que clínicamente suelen ser silentes.

Entre los avances surgidos en los últimos 20 años de historia de la enfermedad se incluyen:

- Creación de registros de ELA.

- Definición y revisión posterior de los criterios diagnósticos (criterios del El Escorial).

- Descubrimiento del riluzol

- Nacimiento de equipos multidisciplinares. 
La incidencia universal de la ELA permanece constante entre 1 y 2 casos nuevos por cada 100.000 habitantes y año. La prevalencia descrita en España es de 5,2 casos por cada 100.000 habitantes. A lo largo de las últimas décadas, se describe un aumento en el número de casos diagnosticados cada año en el resto del mundo, debido probablemente a una mejora en el diagnóstico y a la mayor supervivencia de la población general. LA ELA no familiar es más frecuente en varones (1,78 hombres por cada mujer), aunque esta tendencia tiende a igualarse por encima de los 70 años. Para algunos autores estos datos sugieren que el sexo puede jugar un papel como factor de riesgo de la enfermedad.

\section{Asistencia sanitaria}

Es imprescindible abordar la atención del paciente mediante el control de síntomas, el manejo de los problemas respiratorios,el apoyo psicológico, el apoyo social y la investigación desde unaperspectiva multidisciplinar, garantizando la asistencia al paciente deELA con el nivel de especialización que requiera la enfermedad en cada momento.

Las necesidades de los pacientes se multiplican con la evolución de la enfermedad, por lo que es fundamental la coordinación de todas las actuaciones para trabajar en la misma línea, evitando contradicciones y reforzando las buenas prácticas. La atención temprana a estos pacientes contribuye a su mejor formación y a la de sus familiares para prevenir situaciones de deterioro y afrontar el proceso de dependencia.

Aunque en España no está formalmente reglada la asistencia integral hospitalaria al paciente de ELA, hay experiencias en algunos hospitales españoles que prestan una atención interdisciplinar al paciente y a su familia.

El consenso en esta forma de trabajar entre los distintos profesionales sanitarios obedece a la experiencia en la atención de numerosos casos que se concentran en determinados hospitales. En este sentido cabe mencionar las experiencias de trabajo coordinado para el tratamiento y cuidado del paciente y su entorno familiar de diferentes profesionales en distintos hospitales españoles como son: Hospital de Basurto (País Vasco), Hospital de Bellvitge, Hospital del Mar y Hospital Santa Cruz y San Pablo (Cataluña), Hospital Virgen Macarena, Hospital Virgen del Rocío y Hospital Nuestra Señora de Valme (Andalucía), Hospital Clínico Universitario de Valencia (Comunidad Valenciana), Hospital Central de Asturias y Hospital Clínico de Santiago (Galicia).

En la Comunidad de Madrid en marzo de 2006 se crearon las unidades (Hospital Carlos III, Hospital La Paz, Hospital Gregorio Marañón, Hospital 12 de Octubre y Hospital Clínico San Carlos). 


\section{Abordaje clínico y terapéutico}

Las manifestaciones clínicas de la ELA son debidas al comdel sistema nervioso. La característica clínica más notable es la asociación en un mismo territorio muscular de síntomas y signos, en grado variable, que reflejan la afectación de la neurona motora superior e inferior. La clínica se inicia habitualmente de forma localizada en cualquiera de las cuatro extremidades o en la región cefálica, y puede llegar a producir parálisis progresiva de toda la musculatura esquelética en un plazo aproximado de 2 a 5 años.

Manifestaciones clínicas de la ELA:

- Compromiso específico del sistema motor.

- Asociación en un mismo territorio de síntomas y signos de afectación de neurona motora superior e inferior.

- Inicio localizado.

- Progresión de la parális

Debilidad muscular: Es el síntoma más relevante de la ELA y se debe a la muerte progresiva de neuronas motoras. Se manifiesta cuando se ha perdido el $50 \%$ de la población de neuronas motoras. Inicialmente afecta a un grupo de músculos y se va difundiendo hacia otros a medida que avanza la enfermedad. La pérdida de neuronas motoras corticales no da lugar propiamente a debilidad muscular, sino a torpeza y pérdida de destreza, mientras que el balance de la fuerza muscular puede seguir siendo normal.

Fasciculaciones: Son contracciones espontáneas de un conjunto de fibras musculares inervadas por una misma neurona motora (unidad motora), debidas a alteraciones de la excitabilidad de la membrana de la neurona motora inferior o de su axón.

Calambres musculares: Las rampas o calambres musculares son contracciones dolorosas involuntarias sostenidas de los músculos que se acompañan de contractura palpable, de 30 a 45 segundos de duración.

Hipotonía y arreflexia: La pérdida de tono muscular y la ausencia de reflejos miotáticos son características de las parálisis periféricas. Se pueden observar en las formas de atrofia muscular primaria, aunque en la ELA, la característica es la presencia de reflejos exaltados o patológicos en territorios con debilidad muscular.

Espasticidad: Como consecuencia de la ausencia de relajación de los músculos antagonistas, el tono muscular en estos músculos aumenta, dificultando los movimientos en los que participan grupos musculares antagónicos. 
Hiperreflexia: Los reflejos musculares profundos, regulados por el arco reflejo miotático a nivel medular, quedan liberados a consecuencia de la pérdida del control por parte de la neurona motora cortical.

Reflejos patológicos: A diferencia de los reflejos miotáticos, que son monosinápticos, los reflejos patológicos son polisinápticos, pues en su génesis intervienen múltiples sinapsis neuronales a distintos niveles del sistema nervioso. Se recomienda explorarlos de forma sistemática, ya que su presencia corrobora la afectación de neurona motora superior.

Labilidad emocional: También conocida como risa y llanto espasmódicos. E paciente presenta accesos de risa o lloro de forma incontrolada ante mínimos estímulos emocionales o incluso sin una causa aparente. Es una manifestación característica del síndrome pseudobulbar.

\section{Formas de inicio}

Los primeros síntomas de la enfermedad se manifiestan por la aparición sin causa aparente, en ocasiones después de un traumatismo, de debilidad y pérdida de fuerza localizadas en un grupo muscular inervado por uno o más miotomas adyacentes, en cualquiera de las cuatro extremidades o en la región cefálica (bulbar). Los síntomas iniciales más frecuentes que motivan que el paciente consulte son:

- En las extremidades superiores, pérdida de fuerza en la mano, que se manifiesta al inicio por dificultad para abrir una pinza de tender la ropa, abrocharse los botones de la camisa, o coger objetos. Con menor frecuencia también puede manifestarse por debilidad a nivel más proximal que provoca dificultad para levantar pesos o mantener los brazos extendidos.

- En las extremidades inferiores, debilidad en el pie. Los síntomas más precoces son la imposibilidad para extender el dedo gordo o el pie caído, que puede comportar torceduras repetidas del tobillo. Esta forma de inicio se denomina clásicamente "pseudopolineurítica". Al igual que en las superiores, también puede iniciarse por debilidad a nivel más proximal.

- En cabeza y cuello, la debilidad de los músculos de la lengua y de la faringe da lugar a disartria y disfonía, con dificultad progresiva para pronunciar palabras, especialmente las consonantes linguales y palatales. También, aunque menos frecuente en las fases iniciales, puede ocasionar dificultades para la deglución (disfagia), especialmente de líquidos, lo que puede provocar episodios de tos por el paso del líquido a la tráquea.

- En un $2 \%$ de casos se inicia por síntomas respiratorios, debidos a que la debilidad muscular afecta precozmente a los músculos respiratorios, especialmente al diafragma. 


\section{Formas clínicas}

El diagnóstico de ELA requiere la asociación de signos de neurona motora superior e inferior. Sin embargo, al inicio de la enfermedad los signos de una de ellas pueden estar ausentes. Esto ha llevado a la descripción de distintas formas clínicas en función de la semiología predominante:

1. Forma clásica de ELA.- Asocia hallazgos típicos de neurona motora cortical y medular; suele iniciarse en extremidades superiores y progresar en poco tiempo hacia el resto de la musculatura, incluida la bulbar.

2. Esclerosis lateral primaria.- Se manifiesta exclusivamente por un síndrome de neurona motora cortical y de sus vías córticoespinal y bulbar; la supervivencia de los afectados suele ser superior a los 5 años.

3. Amiotrofia espinal progresiva (atrofia muscular primaria).- Se manifiesta por signos de neurona motora medular, los signos de neurona motora superior están ausentes. Su progresión suele ser más lenta. En esta forma hay que plantearse siempre el diagnóstico diferencial con las amiotrofias espinales hereditarias y neuropatías motoras con bloqueos de conducción.

\section{Diagnóstico}

El diagnóstico de la enfermedad es principalmente clínico y también electrofisiológico.

En el año 1990, la Federación Mundial de Neurología estableció los criterios diagnósticos conocidos como criterios de El Escorial, en la reunión que tuvo lugar en esa ciudad. Dichos criterios permanecen vigentes tras su revisión en 1998, momento en el que se establecen los criterios de arlie en los que se añaden a los criterios clínicos pruebas de laboratorio (electromiografía, neuroimagen,..)

A pesar de esto, el diagnóstico temprano de la enfermedad sigue siendo muy dificultoso y el tiempo que transcurre entre la aparición de los primeros síntomas hasta la confirmación del diagnóstico puede prolongarse hasta 9-14 meses o incluso más según series de diferentes países.

Las principales causas en el retraso en el diagnóstico son la falta de familiaridad de muchos médicos con la enfermedad, la presentación con formas inusuales, la coexistencia de otra enfermedad o los falsos negativos ante la existencia de hallazgos neurorradiológicos que no justifican la enfermedad. 


\section{Tratamiento rehabilitador}

El tratamiento neurorrehabilitador pretende mantener el mayor nivel de calidad de vida del paciente, mejorar su adaptación al entorno, aumentar su autonomía y resolver las complicaciones que vayan surgiendo. Es muy importante mantener la coordinación del equipo que interviene en el tratamiento del paciente, para no incurrir en contradicciones que puedan añadir inseguridad o desconfianza en los pacientes.

a) Medicina física y rehabilitación: El papel de la medicina física en la ELA comienza antes de que haya una pérdida significativa de la fuerza o de la función, y continúa durante el resto de vida de la persona.

Fisioterapia: Se debería iniciar desde el momento en que se conoce el diagnóstico, planificando el ejercicio físico para corregir las alteraciones de la postura, prevenir el dolor y disminuir la rigidez muscular. Asimismo se debe promover la independencia funcional, entrenar al paciente para la prevención de caídas, y reeducar la marcha mediante determinadas ayudas técnicas. Los ejercicios deben hacerse diariamente y convertirse en una rutina.

La terapia ocupacional tiene como objetivo mantener y/o compensar la función deteriorada y preservar la máxima autonomía y calida de vida, además, debe evaluar al paciente e instruirle a él o al cuidador sobre los ejercicios apropiados, asesorando sobre cómo facilitarle las AVD.

Las ayudas técnicas pueden ayudarle a prolongar el tiempo en que puede realizar las AVD con independencia y protegerle de lesiones innecesarias, El terapeuta ocupacional debe tener en cuenta el perfil progresivo de los pacientes de ELA, por lo que no se deben introducir las ayudas demasiado pronto para no provocarle frustración ni demasiado tarde para que no pierdan su efectividad.

Desde hace años, en el manejo de estos enfermos el concepto de ayudas a los músculos respiratorios ha sustituido al de rehabilitación respiratoria convencional. El ambú con circuito, filtros antimicrobianos y máscara oronasal o boquilla, el Cough-Assist y los distintos tipos de ventilador constituyen el soporte instrumental básico de estas ayudas.

Rehabilitación neuropsicológica: La rehabilitación neuropsicológica ayuda al paciente a optimizar la recuperación de sus funciones superiores, a comprender mejor la naturaleza de las alteraciones que presenta y a desarrollar estrategias que permitan compensar estos trastornos.

Intervención logopédica

Evaluación y tratamiento de la disfagia: La evaluación de la disfagia, además de la anamnesis, requiere exploración funcional, exploración con alimentos y videofluoroscopia. La exploración funcional y la exploración con alimentos 
sirven para valorar la fase oral y dan algunos indicios sobre la fase faríngea, pero no detectan la aspiración silente. Si el paciente no presenta tos y se sospecha aspiración, el pulsioxímetro puede ayudar a detectarla. El examen videofluoroscópico permite objetivar la presencia de aspiración, la causa de la misma y especificar las consistencias y volúmenes de los alimentos seguros para el paciente, así como otros tratamientos específicos.

Evaluación y tratamiento de la disartria: Para evaluar la disartria se valoran la motricidad oral, la respiración (patrón, capacidad), la voz (timbre, tono, intensidad), la articulación, la prosodia y el ritmo, así como la inteligibilidad y los recursos comunicativos del paciente. En el tratamiento de la disartria debe incluirse al familiar o cuidador.

\section{¿Existe algún tratamiento?}

Por ahora no existe ningún tratamiento probado contra la E.L.A. el tratamiento debe ser integral, multidisciplinar y comenzar desde el mismo momento de la comunicación del diagnóstico al paciente y a sus familiares.

Además del tratamiento etiopatogenico, se debe abordar un tratamiento sintomático para mejorar la calidad de la vida del paciente y el tratamiento rehabilitador.

El tratamiento sintomático incluye el cuidado nutricional, la sialorrea, dolor calambres, espasticidad, labilidad emocional, depresión, y otros...

En cualquier caso, en la "Guía para la atención de la Esclerosis Lateral Amiotrófica en España" puede conocer todo lo referente a la enfermedad, su diagnóstico, tratamiento, cuidados, etc. Esta a su disposición y se la podemos remitir cuando la solicite.

\section{Investigación}

En la última década se han realizado importantes avances en el conocimiento de la etiopatogenia de la enfermedad, gracias a la investigación básica y terapéutica.

La investigación básica se centra en el estudio de las hipótesis etiopatogénicas que reúnen una mayor evidencia como las alteraciones genéticas ya mencionadas, la disfunción del metabolismo mitocondrial, la excitotoxicidad mediada por el ácido glutámico (principal neurotransmisor excitador del SNC) y la activación de mecanismos de muerte celular programada (apoptosis), mecanismos interrelacionados que conducen a la muerte celular (ver apartado 3.5.1. Tratamiento etiopatogénico). 
La investigación terapéutica se centra en la búsqueda de nuevos tratamientos basados en el conocimiento de los mecanismos básicos citados. Este tipo de investigación se facilita por la existencia de diversos modelos experimentales con ratones transgénicos de la enfermedad, que permiten estudiar previamente el efecto de los posibles tratamientos antes de pasar a una fase de ensayos clínicos.

Se pueden diferenciar cuatro líneas principales de investigación: Medicamentos, factores neurotróficos, terapia génica y tratamientos celulares.

Medicamentos: En los últimos años se han publicado los resultados de varios ensayos clínicos con diferentes fármacos que tienen mecanismos de actuación muy variados y que desafortunadamente no han mostrado eficacia (gabapentina, topiramato, oxandrolona, pentoxifilina, celecoxib, indinavir, coenzima $Q 10$, vitamina $E$, creatina). También se han ensayado moléculas nuevas, no comercializadas (ONO 2506 PO, TCH 346, xaliprodem), que tampoco han demostrado eficacia.

Factores neurotróficos: Son moléculas implicadas en la supervivencia neuronal. Los resultados con BDNF no han sido positivos, mientras que los resultados de los diferentes ensayos con IGF-1 son contradictorios. Con la eritropoyetina hay evidencia de eficacia en algún caso aislado, pero sin confirmación en modelos de experimentación animal y en cualquier caso no es segura por las complicaciones trombóticas que presenta. EI VEGF ha mostrado eficacia en fase preclínica.

Terapias génicas: Su objetivo es interferir en el curso de la enfermedad a través de la modificación de ciertos genes. Las estrategias que se emplean son varias. En todas ellas se trata de ensayos en fase preclínica y con modelos de experimentación animal.

- El uso de transportadores virales administrados por vía intramuscular, con genes que expresan tanto VEGF como IGF-1, ha demostrado resultados positivos.

- También se ha demostrado en cultivos celulares que la administración de virus con el gen que expresa EAAT (recaptador del ácido glutámico) aumenta la captación de ácido glutámico del medio.

- La modificación en dos puntos clave de la secuencia de aminoácidos en la SOD-1 mutada inhibe la formación de agregados, impidiendo el desarrollo de la enfermedad.

- El papel que puede jugar la glía en la patogenia de la enfermedad es cada vez más evidente, como queda reflejado en un estudio en el que actuando sobre modelos en los que se ha retirado de la microglía el 
gen de la SOD-1 mutada, las neuronas con SOD-1 mutada pueden sobrevivir más tiempo.

- En 1998 Fire y Melo publicaron la existencia de un mecanismo por el cual se puede silenciar un gen o lo que es lo mismo, su capacidad de sintetizar proteínas. Por ello, estos autores han recibido el Premio Nobel de Medicina en el año 2006. La técnica del silenciamiento génico o del RNA de interferencia (RNAi) ya se ha aplicado en modelos experimentales de la enfermedad y es una aproximación prometedora de un posible tratamiento, en principio para las formas familiares ligadas a mutaciones de la SOD-1, que podría extenderse a otras alteraciones genéticas conocidas. Consiste en interrumpir las instrucciones génicas para que se sintetice la SOD-1. Se han ensayado dos aproximaciones, ambas con resultado satisfactorio: la primera consiste en inyectar directamente un vector viral en la médula espinal con RNAi, y en la segunda, en administrar por vía IM un vector lentiviral con RNAi, llegando a las neuronas motoras por transporte retrógrado.

Terapia con células madre: Existen dos posibilidades de tratamiento, una con células madre embrionarias $(\mathrm{CME})$ y otra, con células madre adultas endógenas (CMAE).

- Las $C M E$ se obtienen de la masa celular interna del blastocito una semana después de la fertilización del óvulo, siendo, por tanto, células pluripotenciales. Estas células tienen la propiedad de poder aislarse y propagarse en cultivos celulares, con la potencialidad de convertirse en cualquier tipo de tejido. Se ha conseguido la diferenciación en este tipo de cultivos de CME a neuronas motoras, presentando éstas la capacidad de poder formar conexiones con otras neuronas vecinas.

A nivel experimental se ha comprobado que las CME humanas (CMEH) pueden trasplantarse y sobrevivir largos periodos de tiempo en áreas dañadas, pero no se ha evidenciado una clara recuperación funcional.

Otra posibilidad de tratamiento combina aspectos de terapia génica y celular en un modelo experimental en el que las CMEH son modificadas a través de un lentivirus con un gen productor de un factor neurotrófico, concretamente de GDNF (factor neurotrófico derivado de la glía) humano, que se trasplanta a la médula espinal de un ratón transgénico, evidenciándose la supervivencia de las células durante semanas y la producción constante del factor neurotrófico en el lugar requerido.

Las CME también permiten estudiar cómo se produce la diferenciación en los diferentes tipos de tejidos y abre la posibilidad, una vez diferenciadas, de investigar nuevos fármacos, antes de realizar ensayos clínicos. En este sentido es interesante la creación de los llamados híbridos celulares a través de la fusión de una $\mathrm{CMEH}$ con una célula 
adulta de la piel. Aunque no pueden utilizarse para trasplante porque tienen el doble de cromosomas, ya que contienen los genes de ambos tipos celulares, sólo expresan las propiedades de las células embrionarias. De hecho, la técnica transfiere una célula adulta a un estado embrionario, siendo esta célula, a su vez, capaz de sobrevivir, crecer y producir todo tipo de células.

- Las células madre adultas endógenas (CMAE) se encuentran, por ejemplo, en la médula ósea y también se ha comprobado su existencia en el cerebro y en la médula espinal. Son células multipotenciales y su capacidad de regeneración de un tejido dañado es menor. Sin embargo, hoy en día se está viendo que pueden desarrollar efectos beneficiosos cuando se trasplantan en el sistema nervioso central. Aunque se ha visto que las células madre neurales del adulto presentan cierta dificultad para proliferar en cultivos de laboratorio, la capacidad regenerativa de las células madre de médula ósea en el organismo ha permitido el desarrollo de la terapia celular en hematología.

A nivel experimental se ha comprobado que CMAE de medula ósea trasplantadas en ratones han migrado al cerebro y se han convertido en células que parecen neuronas. También se han trasplantado CMAE de bulbo olfatorio de un ratón adulto en un modelo de ratón transgénico, apreciándose aumento de la supervivencia.

Las CMAE cerebrales pueden ser una alternativa al trasplante, si se pudiera estimular su crecimiento. Ya hay líneas de investigación sobre los genes y moléculas que intervienen en la división celular, migración y especialización de estas células que se encuentran en determinadas regiones cerebrales como el bulbo olfatorio.

En modelos animales de ELA se ha visto que el trasplante de células madre de médula ósea en la médula espinal ha mejorado la función motora de los animales y reduce la muerte de neuronas motoras, gracias a un efecto neurotrófico de las células madre. Este efecto neuroprotector de las células madre puede ser una prometedora vía de uso de terapia celular en la que las células actúan como vehículos de factores beneficiosos para otras células enfermas.

La Fundación Diógenes para la Investigación de la ELA ha iniciado dos líneas de investigación básicas en el Instituto de Neurociencias de la Universidad Miguel Hernández de Elche. De la primera línea, abierta en el 2001, se ha conseguido el inicio de un ensayo clínico en fase I/II de utilización de células madre de médula ósea autólogas en pacientes con esclerosis lateral amiotrófica, que se está llevando a cabo en dos hospitales de la ciudad de Murcia, tiene una duración de tres años y su finalidad es conseguir enlentecer la degeneración de las neuronas motoras. El otro proyecto de trabajo iniciado estudia la regeneración de neuronas motoras espinales a partir de células madre embrionarias. 